\title{
Cell-surface properties of Lactococcus garvieae strains and their immunogenicity in the yellowtail Seriola quinqueradiata
}

\author{
Tsuyoshi Ooyama ${ }^{1}$, Yusuke Hirokawa ${ }^{2}$, Takayuki Minami ${ }^{1}$, Hiroshi Yasuda ${ }^{1}$, \\ Toshihiro Nakai ${ }^{3}$, Makoto Endo ${ }^{2}$, Lila Ruangpan ${ }^{4}$, Terutoyo Yoshida ${ }^{2, *}$ \\ ${ }^{1}$ Miyazaki Prefectural Fisheries Experimental Station, Miyazaki Prefecture, Aoshima, Miyazaki 6-16-3, Japan \\ ${ }^{2}$ Department of Fisheries, Faculty of Agriculture, Miyazaki University, Miyazaki 889-2192, Japan \\ ${ }^{3}$ Faculty of Applied Biological Science, Hiroshima University, Higashihiroshima 739-8528, Japan \\ ${ }^{4}$ Samutsakhon Coastal Aquaculture Development Centre Kkkham, Muang, Samutsakhon 74 000, Thailand
}

\begin{abstract}
The cell-surface properties of strains of Lactococcus garvieae were examined. Two capsular types were found, one with a highly developed capsule (KG9408) and one with a micro-capsule (MS93003) carrying fimbriae-like components projecting from the cell surface. One strain (NSS9310) had neither cell capsular nor fimbriae-like structures on its cell surface. The strains with the highly developed capsule were more virulent to fish than either the micro-capsular or non-capsular strains. The KG9408, MS93003 and NSS9310 strains could be clearly differentiated by their susceptibility to bacteriophages. Protection against $L$. garvieae infection was induced in the yellowtail Seriola quinqueradiata by immunization with formalin-killed L. garvieae KG9408 and MS93003 cells. Although protection was also induced by immunization with NSS9310, the level of protection was significantly lower than that with KG9408 and MS93003 vaccines. Passive immunization with yellowtail immune sera raised against KG9408 and MS93003 conferred strong protection on yellowtail with rapid bacterial clearance after challenge with $L$. garvieae. Immunoblotting analysis of protein antigens extracted from L. garvieae strains using rabbit anti-KG9408 and anti-MS93003 sera and yellowtail anti-KG9408 and anti-MS93003 sera indicated that some bands in KG9408 and MS93003 strains were not detectable in NSS9310.
\end{abstract}

KEY WORDS: Immunogenicity $\cdot$ Lactococcus garvieae $\cdot$ Seriola quinqueradiata $\cdot$ Cell capsule $\cdot$ Fimbriae

\section{INTRODUCTION}

Lactococcus garvieae is a serious bacterial pathogen of the yellowtail Seriola quinqueradiata and amberjack S. dumullei in Japan (Kusuda et al. 1991, Kitao 1993). It has also been isolated from the rainbow trout Oncorhynchus mykiss in Italy (Eldar et al. 1996, 1999) and Australia (Carson et al. 1993, Schmidtke \& Carson 1999), and from the prawn Macrobranchium rosenbergii in Taiwan (Chen et al. 2001). L. garvieae isolated from $S$. quinqueradiata has been divided into non-

${ }^{*}$ Corresponding author. E-mail: t-yosh@Cc.miyazaki-u.ac.jp agglutinating (KG-phenotype) and agglutinating (KG+ phenotype) phenotypes using anti-KG+ phenotype serum (Kitao 1982, Yoshida et al. 1996, 1997, Ooyama et al. 1999). The KG- phenotype was agglutinated by anti KG- phenotype cell serum (but not by antisera to the KG+ phenotype, KG7409). However, KG+ phenotype strains were agglutinated with antisera to both KG+ and KG- phenotypes (Kitao 1982, 1993). Furthermore, in KG-phenotype cells incubated with anti KGphenotype serum and stained with ruthenium red, cell capsules adjacent to the cell wall were visible by electron microscopy. This capsulated phenotype strain is more virulent to the yellowtail than non-capsulated strains (Alim et al. 1996). Therefore, these capsules are 
thought to play roles in the pathogenicity of L. garvieae infection, possibly by increasing resistance to fish phagocytosis (Yoshida et al. 1996, 1997).

Control of Lactococcus garvieae infection in yellowtail culture has depended on chemotherapy with macrolides. The identification of multiple drug-resistant strains has indicated future problems in controlling the pathogen (Aoki et al. 1990). Recently, oral and injectable vaccines against $L$. garvieae infection in Seriola quinqueradiata have been developed and commercialized in Japan. Experimental vaccination against $L$. garvieae has been described (Iida et al. 1982, Sato et al. 1996) and has been reported to provide immunity and increased opsonic activity in the fish. However, no detailed information on the antigenicity of $L$. garvieae phenotypes nor the duration of the immunity was given. The protective mechanisms of the $L$. garvieae vaccine remains unknown.

In a previous study, Ooyama et al. (1999) reported that formalin-killed Lactococcus garvieae KG- phenotype (capsulated phenotypes) cells and KG+ phenotype (noncapsulated) cells induced strong immunity in Seriola quinqueradiata against artificial infection and longlasting agglutinating titres against non-capsulated cells (avirulent KG+ phenotype). Furthermore, appendages (fimbriae-like structures) were seen extending from the cell surface of L. garvieae KG- phenotype, with some destruction of the cell capsule, after opsonization with yellowtail immune serum. Both formalin-killed cells of the KG-and KG+ phenotypes were effective against infection with $\mathrm{KG}$ - virulent phenotype cells, suggesting that the antigen providing immunity against L. garvieae infection is located on the cell surface or projects into the cell capsules from the surface, and is not present in the cell capsules themselves.

Recently, some strains of Lactococcus garvieae $\mathrm{KG+}$ phenotype were found that induced a weak immune response in fish against capsulated virulent $\mathrm{KG}$ - phenotype infection. The aim of the present study was to re-examine the cell-surface properties of various L. garvieae strains and compare the immune response of Seriola quinqueradiata to these strains.

Table 1. Lactococcus garvieae strains used in this study

\begin{tabular}{|c|c|c|c|c|}
\hline Strain & Year & $\begin{array}{l}\text { Sources } \\
\text { (prefectures) }\end{array}$ & $\begin{array}{c}\text { Pheno- } \\
\text { types }\end{array}$ & Source \\
\hline NG8206 & 1982 & Nagasaki & $\mathrm{KG}+$ & $\begin{array}{l}\text { Yoshida et al. }(1996,1997), \\
\text { Ooyama et al. (1999), } \\
\text { Okada et al. (2000) }\end{array}$ \\
\hline MS93003 & 1993 & Miyazaki & $\mathrm{KG}+$ & Ooyama et al. (1999) \\
\hline NSS9310 & 1993 & Nagasaki & $\mathrm{KG}+$ & This study \\
\hline KG9408 & 1994 & Kagoshima & $\mathrm{KG}-$ & This study \\
\hline
\end{tabular}

\section{MATERIALS AND METHODS}

The bacterial strains are listed in Table 1. All were cultured in Todd-Hewitt broth (THB; Difco) or on agar (THA). Immune sera against the NG8206 KG+ phenotype (non-capsulated cells) and KG9408 KGphenotype (capsulated cells) were raised in rabbits, as described by Yoshida et al. (1996). The KG+ phenotypes (NG8206, NSS9310 and MS93003) stemmed from a subculture of the $\mathrm{KG}$ - parent on THA supplemented with 2,3,5-triphenyltetrazolium chloride (TTC) as previously described by Ooyama et al. (1999).

The yellowtail fish Seriola quinqueradiata used in the experiment were bred at Miyazaki Experimental Fisheries Station, Aoshima, Miyazaki, Japan, and kept in concrete tanks with sand-filtered sea water. The fish were fed commercial dried pellets once a day. Before the experiment, the fish $(\mathrm{n}=10)$ were subjected to bacterial examination to determine the presence of Lactococcus garvieae.

The bacteria were cultured in THB at $25^{\circ} \mathrm{C}$ without shaking for $24 \mathrm{~h}$. Cells were harvested by centrifugation and suspended in sterile saline solution $(0.85 \% \mathrm{NaCl})$. Serial dilutions were prepared in the saline solution, and viable counts were determined by plating on THA. Virulence was tested with 10 fish (approximately $20 \mathrm{~g}$ ) per dilution inoculated intraperitoneally with $0.1 \mathrm{ml}$ of each bacterial suspension: $3.2 \times 10^{3}, 3.2 \times 10^{4}$ and $3.2 \times 10^{5}$ CFU ml ${ }^{-1}$ for KG9408 (KG- phenotype cells), $5.2 \times 10^{5}$, $5.2 \times 10^{5}$ and $6.2 \times 10^{5} \mathrm{CFU} \mathrm{ml}^{-1}$ for NSS9310, MS93003 and NG8206 (KG+ phenotype cells), respectively. The fish were maintained at 24 to $26^{\circ} \mathrm{C}$ for $14 \mathrm{~d}$ in separate tanks. Non-treated fish were injected with saline as controls. Virulence was expressed as the $50 \%$ lethal dose, $\mathrm{LD}_{50}$ (Reed \& Muench 1938).

Transmission electron microscopy (TEM) was performed as described by Yoshida et al. (1997). Briefly, Lactococcus garvieae KG- and KG+ (KG9408, MS93003 and NSS9310) were grown overnight in $10 \mathrm{ml}$ of THB, diluted 1:100 in fresh THB, and incubated for an additional $5 \mathrm{~h}$ at $25^{\circ} \mathrm{C}$. Bacteria were washed with phosphate-buffered saline (PBS) and fixed with $2.5 \%$ glutaraldehyde. The cells were washed 3 times with PBS and resuspended in $10 \mathrm{ml}$ of anti-KG- rabbit serum (agglutinating titre against KG9408, KG-phenotype cells; 1:1280) diluted 200 times with PBS and incubated for an additional hour before staining with $0.15 \%$ ruthenium red in 0.1 M cacodylate buffer, $\mathrm{pH} 7.4$ for $2 \mathrm{~h}$. Bacteria were washed 3 times with PBS, embedded in $3 \%$ agarose, fixed with $2 \%$ osmium tetroxide, washed 5 times with cacodylate buffer, and 
dehydrated with ethanol. Cells were embedded in Quetol 652 (Nishin EM, Tokyo, Japan). Thin sections were cut $(60 \mathrm{~nm})$, post-stained with uranyl acetate and lead acetate, and observed by transmission electron microscopy (Hitachi-H4800Mu, Japan) at an accelerating voltage of $100 \mathrm{kV}$. For investigation of fimbriae-like structures on the cell surface, bacterial strains were cultured in $10 \mathrm{ml}$ of normal filter-sterilised yellowtail serum $(100 \%)$ at $25^{\circ} \mathrm{C}$ for $48 \mathrm{~h}$, were washed twice with PBS, and fixed with $2 \%$ glutaraldehyde. Samples for TEM were treated as described above.

Lactococcus garvieae bacteriophage strains PLgY-16, PLgY-30 and PLgW-1 were used in this study (Park et al. 1997, 1998). The phages were propagated on $L$. garvieae NSS9310 (indicator bacterium) by the double agar-overlay method (Paterson et al. 1969), and the susceptibilities of $L$. garvieae strains were then assessed by plaque formation using the same method.

KG9408, MS93003 and NSS9310 strains were cultured in THB and killed by addition of a final concentration of $0.3 \%$ formaldehyde. Bacterial cells were washed 3 times with phosphate-buffered saline and adjusted to 1.0 at an o.d. of $660 \mathrm{~nm}$. Yellowtail (200 to $250 \mathrm{~g}, \mathrm{n}=26 \times 3$ ) were immunized with each bacterin (KG9408, MS93003 and NSS9310); 14 d later, each immunized fish $(\mathrm{n}=16 \times 3)$ were injected intraperitoneally with KG9408 KG-phenotype cells at a density of $2.5 \times 10^{5}$ cells fish $^{-1}$. The fish was monitored daily for $14 \mathrm{~d}$, and individuals that died were subjected to bacteriological examination to verify the cause of death. Immunized fish $(\mathrm{n}=10 \times 3)$ without infection were bled to provide immune serum $14 \mathrm{~d}$ after immunization. Untreated control fish $(\mathrm{n}=26)$ were injected with saline; 14 d later, a further 16 fish were infected with the same dose of KG9408 (KGphenotype cells). Normal serum were isolated from fish ( $\mathrm{n}=10$ ) with no infection $14 \mathrm{~d}$ after sham-injection (saline). Fish sera from each immunized and control fish were filtered through a $0.45 \mu \mathrm{m}$ pore-size filter (Sartorius), and kept at $-80^{\circ} \mathrm{C}$ until use. Immune sera from each were pooled for all immunized fish and also for all untreated fish, respectively, for passive immunization tests and immunoblot analysis. Agglutinating titres of immune sera against KG9408, MS93003 and NSS9310 were measured by a microplate assay according to Roberson (1990). Throughout the experiment, from immunization to the challenge test, the water temperature was between 24 and $26^{\circ} \mathrm{C}$.

Yellowtail (75 to $105 \mathrm{~g} ; \mathrm{n}=13 \times 3$ ) were inoculated intraperitoneally with $3 \mathrm{ml}$ of immune serum from fish immunized with KG9408, MS93003, or NSS9310 formalin-killed cells. Control fish $(\mathrm{n}=13)$ were given $3 \mathrm{ml}$ of normal yellowtail serum from untreated healthy fish (200 to $250 \mathrm{~g} ; \mathrm{n}=10$ ). The fish were challenged intraperitoneally $30 \mathrm{~h}$ later with KG9408 KG- pheno- type cells at a density of $2.5 \times 10^{4}$ cells fish $^{-1}$, and were monitored for $14 \mathrm{~d}$. At the end of this period, all fish were subjected to bacteriological examination for the presence of Lactococcus garvieae in the brain and kidney; $30 \mathrm{~h}$ after infection, 3 fish were also sampled for bacteriological counts in the blood, spleen and brain using plate counts. These organs and blood were aseptically sampled, and homogenized in phosphatebuffered saline supplemented with heparin $\left(100 \mu \mathrm{ml}^{-1}\right)$, diluted, and spread over THA plates supplemented with $0.025 \%$ TTC. Colony-forming units (CFU) of L. garvieae were counted after $72 \mathrm{~h}$ incubation at $25^{\circ} \mathrm{C}$ and expressed as CFU g ${ }^{-1}$ for the brain and spleen, or CFU ml ${ }^{-1}$ for the blood. Throughout the experiment, from passive immunization to the infection test, the water temperature was between 24 and $26^{\circ} \mathrm{C}$.

KG9408 formalin-killed cells were heated to 100 or $121^{\circ} \mathrm{C}$ for $15 \mathrm{~min}$, or left untreated (kept at $4^{\circ} \mathrm{C}$ ) to compare the heat stability of the antigens that conferred the protection on the fish. Fish (45 to $60 \mathrm{~g}$; $\mathrm{n}=10 \times 3$ ) were immunized with each heat-treated or untreated bacterial cells. Control fish $(\mathrm{n}=10)$ were injected intraperitoneally with saline. Fish were challenged intraperitoneally with KG9408 cells at a density of $2.1 \times 10^{6} \mathrm{CFU}$ fish $^{-1} 14 \mathrm{~d}$ after immunization, and were monitored for a further $14 \mathrm{~d}$. Throughout the experiment, from immunization to the infection test, the water temperature was between 24 and $26^{\circ} \mathrm{C}$.

Whole-cell protein extracts were prepared as described by Carson et al. (1993). Proteins were separated by SDSpolyacrylamide gel electrophoresis using $12.5 \%$ acrylamide-separating gel with $2.5 \%$ stacking gel (Laemmli 1970). Proteins were blotted onto transfer membranes (Immobilon ${ }^{\mathrm{TM}}-\mathrm{P}$ Transfer Membrane, Millipore) as described by Towbin et al. (1979). Immunoblotting analysis of protein extracts from KG9408, MS93003 and NSS9310 were performed using rabbit anti-KG9408 and anti-MS93003 sera, and yellowtail anti-KG9408 and antiMS93003 sera. A rabbit anti-yellowtail immunoglobulin serum was prepared according to Smith (1992). Yellowtail anti-KG9408 and anti-MS93003 sera, rabbit antiyellowtail immunoglobulin, and rabbit anti-KG9408 and anti-MS93003 sera were diluted 1:100, 1:1000 and 1:500, respectively. The antibodies bound to proteins immobilized on the membranes were detected with alkaline phosphatase-conjugated goat anti-rabbit immunoglobulin G (IgG; Sigma) and developed by addition of 5-bromo4-chloro-3 indolyl phosphate as the substrate, and nitroblue tetrazolium salt as the developer.

Statistical analyses of the protective efficacy of the vaccines and passive immunizations were performed by Fisher's protected least-squares difference test. The significance of the different plaque sizes of bacteriophage PLgw-1 on KG9408, MS93003 and NSS9310 was analysed using Welch's test. 
Table 2. Lactococcus garvieae. Lethal doses causing 50\% mortality $\left(\mathrm{LD}_{50}\right)$ in the yellowtail Seriola quinqueradiata, cell capsulation, and fimbriae-like structures of different bacterial strains. +: present; nd: not detected

\begin{tabular}{|lccc|}
\hline Strain & LD $_{50}$ & Capsule & $\begin{array}{c}\text { Fimbriae-like } \\
\text { structure }\end{array}$ \\
\hline NG8206 & $>1.0 \times 10^{5}$ & nd & nd \\
MS93003 & $>1.0 \times 10^{5}$ & micro-capsule & + \\
NSS9310 & $>1.0 \times 10^{5}$ & nd & nd \\
KG9408 & $5.2 \times 10^{3}$ & $100-200 \mathrm{~nm}$ & + \\
\hline
\end{tabular}

\section{RESULTS}

The $\mathrm{LD}_{50}$ of each bacterial strain is shown in Table 2 . Strains with a highly developed capsule KG9408 (KGphenotype cells) were more virulent to the fish than NG8206, MS93003 and NSS9310 (KG+ phenotype cells). Cell capsules ranging from 100 to $200 \mathrm{~nm}$ for KG9408 and micro-capsules (approx. $10 \mathrm{~nm}$ ) for MS93003 were observed after treatment with rabbit anti-KG- phenotype serum. However, no capsule was observed for NSS9310 even after treatment with immune serum. Fimbriae-like structures on the surface of KG9408 and MS93003 were observed when the cells were cultured in yellowtail serum. NSS9310 showed no surface visible components when the cells were cultured in fish serum (Fig. 1).

MS93003 and NSS9310 were highly susceptible to Bacteriophages PLgY-16 and PLgW-1, but KG9408 was not susceptible. Although the titres of bacteriophage PLgY-30 against KG9408, MS93003 and NSS9310 were similar (Table 3), the plaque sizes of PLgW-1 on KG9408 $(0.5 \mathrm{~mm} \pm 0.2)$ were significantly different $(\mathrm{p}<0.05)$ from MS93003 (1.4 $\mathrm{mm} \pm 0.5$ ) and NSS9310 (1.4 mm \pm 0.7 ).

The protective efficacy of vaccines against artificial infection of KG9408-virulent KG- phenotype cells is shown in Table 4. Significantly higher protection was recorded in fish immunized with formalin-killed KG9408 and MS93003 cells compared to untreated fish ( $p<0.01$ ) and fish immunized with NSS9310 formalinkilled cells $(\mathrm{p}<0.05)$. However, some protection was still provided by the NSS9310 vaccine compared to untreated control fish $(\mathrm{p}<0.05)$.

Table 3. Lactococcus garvieae. Bacteriophage susceptibilities of different strains

\begin{tabular}{|lrrr|}
\hline \multirow{2}{*}{ Strain } & \multicolumn{3}{c|}{ Bacteriophage titre } \\
\cline { 2 - 4 } & PLgY-16 & PLgY-30 & PLgW-1 \\
\hline NSS9310 & $2.0 \times 10^{9}$ & $7.0 \times 10^{9}$ & $2.8 \times 10^{9}$ \\
MS93003 & $9.0 \times 10^{9}$ & $2.2 \times 10^{9}$ & $9.6 \times 10^{9}$ \\
KG9408 & $<1.0 \times 10^{5}$ & $3.1 \times 10^{9}$ & $<1.0 \times 10^{5}$ \\
\hline
\end{tabular}

Table 4. Seriola quinqueradiata infected with Lactococcus garvieae KG9408. Fish mortality (no. of dead fish/no. of infected fish) in fish immunized with formalin-killed NSS9310, MS93003 and KG9408 strains of L. garvieae. Results were significantly different from those for untreated fish $\left({ }^{*} p<0.01\right.$; $\left.{ }^{* *} \mathrm{p}<0.05\right)$ and fish immunized with NSS9310 $\left({ }^{* * *} \mathrm{p}<0.05\right)$

\begin{tabular}{|lc|}
\hline Vaccine & Fish mortality \\
\hline NSS9310 & $8 / 16^{* *}$ \\
MS93003 & $0 / 16^{*, * * *}$ \\
KG9408 & $0 / 16^{*, * * *}$ \\
Untreated & $14 / 16$ \\
\hline
\end{tabular}

The agglutinating titres of pooled yellowtail immune sera against KG9408, MS93003 and NSS9310 are shown in Table 5. The agglutinating titres of immune sera against KG9408 ranged from <1:4 to 1:8, while the titres of immune sera against MS93003 and NSS9310 were 1:64 to 1:256. Agglutinating titres of serum from untreated fish against KG9408, MS93003 and NSS9310 were not detected. No mortailities were observed in fish passively immunized with anti-KG9408 or antiMS93003 sera, but fish given anti-NSS9310 were not completely protected against KG9408 infection. Bacteriological examination of surviving fish which had been passively immunized against KG9408 or MS93003 indicated complete eradication of the bacteria. In contrast, bacteria were detectable in the kidney and brain of fish passively immunized against NSS9310 (Table 6). Bacteria were eradicated rapidly from the blood, spleen and brain of fish passively immunized against KG9408 or MS93003, yet were detectable in the blood and spleen but not the brain of fish treated with anti-NSS9310 serum (Table 7).

Treatment of KG9408 formalin-killed cells at $121^{\circ} \mathrm{C}$ for 15 min decreased the protection of the fish against homologous bacterial infection (mortality $=80 \%$ ). Parallel groups of fish immunized with KG9408 treated at $100^{\circ} \mathrm{C}$ for $15 \mathrm{~min}$, or with non-heat treatment (kept at $4^{\circ} \mathrm{C}$ ) and a control group without immunization had mortality rates of 20,0 and $90 \%$, respectively.

Immunoblot analysis of proteins extracted from KG9408, MS93003, NSS9310 and Lactococcus lactis

Table 5. Agglutinating titres of Seriola quinqueradiata immune sera raised against Lactococcus garvieae formalinkilled strains

\begin{tabular}{|lccc|}
\hline \multirow{2}{*}{ Antigen } & \multicolumn{3}{c}{ Serum from fish immunized with } \\
& NSS9310 & MS93003 & KG9408 \\
\hline NSS9310 & $1: 128$ & $1: 256$ & $1: 64$ \\
MS93003 & $1: 256$ & $1: 256$ & $1: 128$ \\
KG9408 & $<1: 4$ & $1: 4$ & $1: 8$ \\
\hline
\end{tabular}


ATCC19435 strains using rabbit anti-KG9408 and antiMS93003 serum, and yellowtail anti-KG9408 and antiMS93003 serum are shown in Fig. 2. Two protein bands, ranging from 30 to 35 and 15 to $20 \mathrm{kDa}$ were missing in the NSS9310 strain compared with the protein profiles of the KG9408 and MS93003 strains using rabbit antiserum against KG9408 and MS93003 (Fig. 2A). Immunoblotting analysis showed that although yellowtail anti-KG9408 immune serum detected protein bands of approximately 30 to 35 and
45 to $50 \mathrm{kDa}$ in the extracts from Strains KG9408 and MS93003, the bands were not observed in NSS9310 strain treated with yellowtail anti-KG9408 serum. With yellowtail anti-MS93003 serum, an increase in staining intensity was observed for detectable antigens of approximately 30 to 35 and 40 to $50 \mathrm{kDa}$ in KG9408 and MS93003 compared with NSS9310 (Fig. 2B). Both rabbit and yellowtail anti-KG9408 and antiMS93003 sera detected several antigens of L. lactis ATCC19435 (Fig. 2A,B).

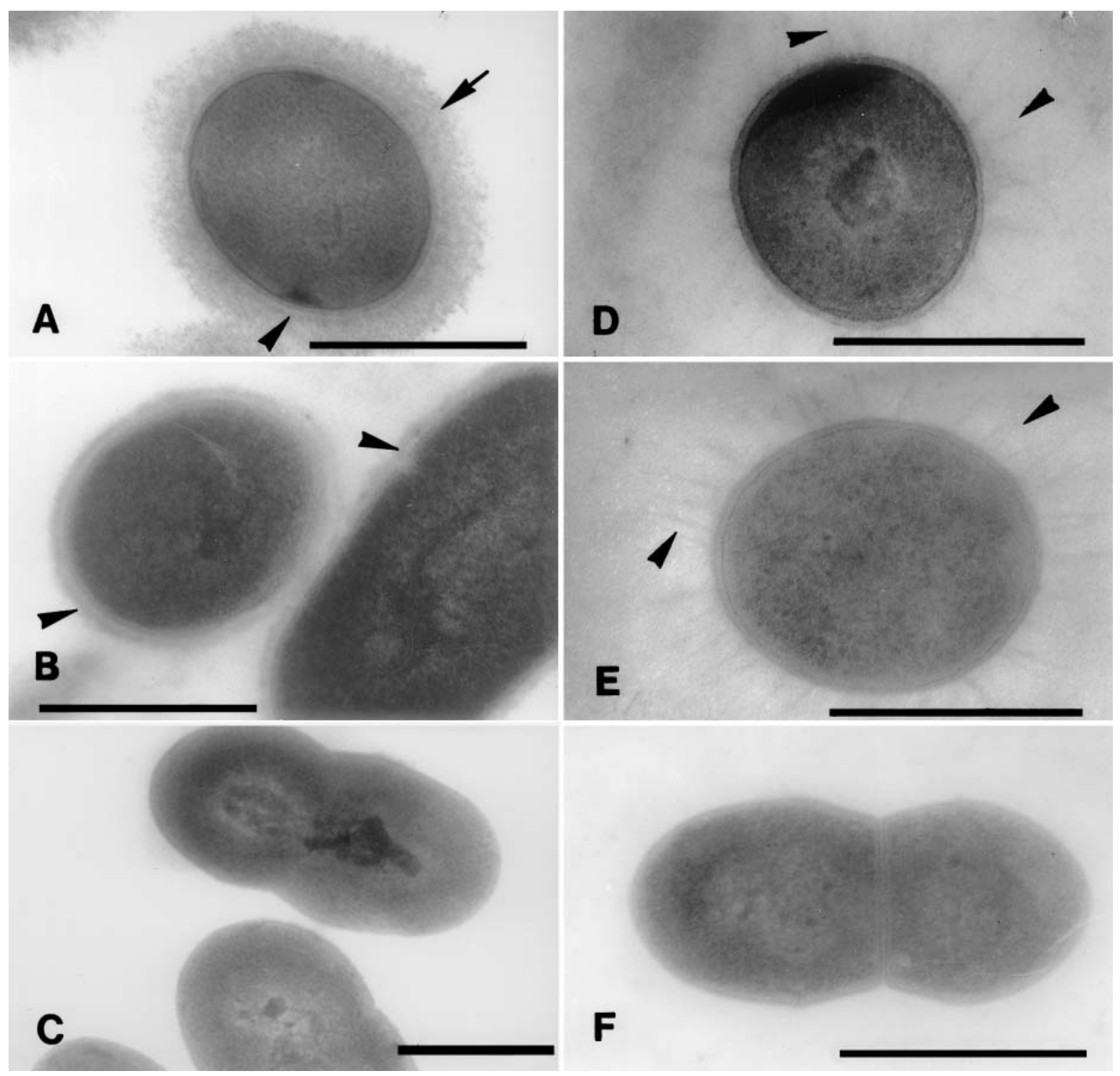

Fig. 1. Lactococcus garvieae. Transmission electron microscopy (TEM) of KG9408, MS93003 and NSS9310 strains. (A-C) Cells treated with antiserum raised against encapsulated KG9408 KG- phenotype cells; (D-F) cells cultured in Seriola quinqueradiata normal serum. (A) Cell, showing well-developed cell capsule (arrow) with faint inside layer (arrowhead); (B) micro-capsule surrounding the cell wall of MS93003 (arrowheads); (C) NSS9370, no cell capsule or micro-capsule visible; (D, E) fimbriae-like structures (arrowheads) projecting from cell surface of KG9408 (D) and MS93003 (E); (F) NSS9310, no cell surface components visible even after culturing in fish normal serum. Scale bars $=1 \mu \mathrm{m}$ 
Table 6. Seriola quinqueradiata. Efficacy of passive immunization of yellowtail against Lactococcus garvieae infection. Fish mortality: no. of dead fish/no. of infected fish, in fish treated with antiserum to KG9408, MS93003 and NSS9310. Survivors $L$. garvieae-positive: no. of survivors in which $L$. garvieae was detected in kidney and brain after sacrifice; results were significantly different from fish passively given normal serum $\left({ }^{*} \mathrm{p}<0.05\right)$

\begin{tabular}{|lcc|}
\hline Implanted serum & Fish mortality & $\begin{array}{c}\text { Survivors } \\
\text { L. garvieae-positive }\end{array}$ \\
\hline KG9408 & $0 / 10^{*}$ & $0 / 10$ \\
MS93003 & $0 / 10^{*}$ & $0 / 10$ \\
NSS9310 & $3 / 10$ & $2 / 7$ \\
Normal serum & $6 / 10$ & $1 / 4$ \\
\hline
\end{tabular}

\section{DISCUSSION}

Antigenic conversion from the $\mathrm{KG}-$ to $\mathrm{KG}+$ phenotype in Lactococcus garvieae occurred after several subcultures on agar media supplemented with TTC. The KG-phenotype (non-agglutinating strain against $\mathrm{KG}+$ antiserum) strains were capsulated and more virulent to fish than the $\mathrm{KG}+$ phenotype (Alim et al. 1996). No cell capsules could be seen by the Indian ink or the 'quellung' method (Yoshida et al. 1997), but after treatment of KG-phenotype cells with antiserum
Table 7. Seriola quinqueradiata. Bacterial counts in blood, spleen and brain of fish passively immunized with yellowtail anti NSS9310, MS93003 and KG9408 sera. nd: not detectable

\begin{tabular}{|ccccc|}
\hline Antiserum & Fish & \multicolumn{3}{c|}{ No. of viable bacteria $\left(\mathrm{CFU} \mathrm{ml}{ }^{-1}\right)$} \\
& no. & Blood & Spleen & Brain \\
\hline NSS9310 & 1 & $2.0 \times 10^{2}$ & nd & nd \\
& 2 & $2.0 \times 10^{2}$ & $3.0 \times 10^{3}$ & nd \\
& 3 & $3.0 \times 10^{3}$ & $2.0 \times 10^{3}$ & nd \\
MS93003 & 1 & nd & nd & nd \\
& 2 & nd & nd & nd \\
& 3 & nd & nd & nd \\
KG9408 & 1 & nd & nd & nd \\
& 2 & nd & nd & nd \\
& 3 & nd & nd & nd \\
Normal & 1 & $7.5 \times 10^{5}$ & $1.3 \times 10^{4}$ & $1.3 \times 10^{5}$ \\
serum & 2 & $1.4 \times 10^{5}$ & $1.0 \times 10^{5}$ & $3.0 \times 10^{4}$ \\
& 3 & $5.4 \times 10^{5}$ & nd & nd \\
\hline
\end{tabular}

raised against the capsulated strain, well-developed capsules were seen on the surface of L. garvieae. Furthermore, KG+ antigens were detected only around the cell surface but not in cell capsules of L. garvieae, whereas KG- antigens were detected spreading over the capsule. Cell capsules inhibited cell agglutination with serum raised against KG+ phenotype cell (noncapsulated cells) and was possibly involved in resistance to fish phagocytosis (Okada et al. 2000). In a previous investigation, formalin-killed $\mathrm{KG}-$ and
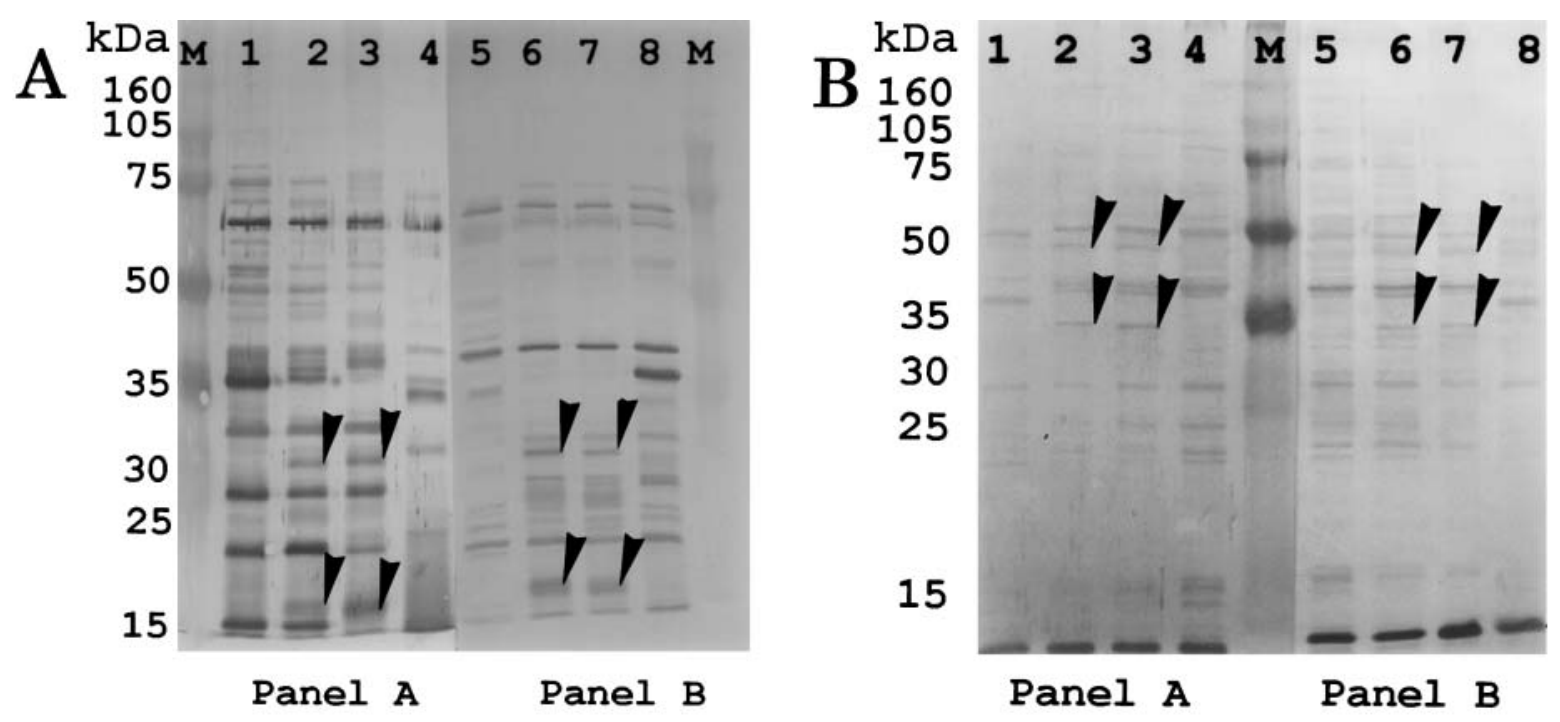

Fig. 2. Lactococcus garvieae. Detection of proteins extracted from KG9408, MS93003 and NSS9310 strains by immunoblotting. (A) Proteins on filters reacted with rabbit anti-KG9408 serum (Panel A) and rabbit anti-MS93003 (Panel B); Lane M: marker proteins; Lanes 1 and 8: NSS9310; Lanes 2 and 7: MS93003; Lanes 3 and 6: KG9408; L. Lanes 4 and 5: L. lactis $19435 ; 2$ proten bands of approximately 15 to 20 and 30 to $35 \mathrm{kDa}$ can be seen in KG9408 and MS93003, but not in NSS9310 (arrowheads). (B) Proteins on filters reacted with yellowtail anti-KG9408 serum (Panel A) and yellowtail anti-MS93003 serum (Panel B); Lane M: marker proteins; Lanes 1 and 8: L. lactis ATCC19435; Lanes 2 and 7: KG9408; Lanes 3 and 6: MS93003; Lanes 4 and 5: NSS9310; increase in staining intensity is seen for proteins of approx. 30 to 35 and 45 to $50 \mathrm{kDa}$ in KG9408 and MS93003 compared to NSS9310 arrowheads 
KG+ phenotype cells induced high protection in Seriola quinqueradiata against artificial infection with capsulated virulent strain (KG-phenotype cells) with immunity lasting at least 6 mo. Therefore, it was speculated that antigens associated with immunity against L. garvieae were located on the bacteria's surface not in the capsules (Ooyama et al. 1999).

In this study, formalin-killed cells of KG9408 and MS93003 also induced a high level of protection in fish against capsulated virulent cells, although the immunity in fish immunized with NSS9310 KG+ phenotype cells was only partial. Passive immunization of yellowtail with yellowtail antisera raised against KG9408 or MS93003 strains also showed rapid bacterial clearance from blood and spleen, and conferred high immunity on the fish. Viable bacteria were recovered from the blood and spleen of fish treated with yellowtail antiNSS9310 strain serum, but at lower levels than from fish injected with non-immune fish serum. These results support previous findings that humoral immunity plays an important role in protection against infection by Lactococcus garvieae (Ooyama et al. 1999, Barnes et al. 2002a,b). They suggest, moreover, that complete immune protection against the infection could be induced with NSS9310 antigens in combination with other antigens.

In a previous study, the MS93003 strain was classified as KG+ phenotype cells with no cell surface components (Ooyama et al. 1999). However, in our detailed observations, a micro-capsule was seen on MS93003 after treatment with anti KG- phenotype rabbit serum. Furthermore, fimbriae-like cell surface components were observed after culture in normal serum from the fish. The $\mathrm{LD}_{50}$ and susceptibility of MS93003 to bacteriophages were similar to those of NSS9310 KG+ phenotype cells, suggesting that a micro-capsule is not as strongly related to degree of virulence as is a well-developed cell capsule.

Attachment to host cells is important in initiating infection by pathogens (Marques et al. 1984). Bacterial lectins and fimbriae are thought to participate in bacterial attachment to animal cells or erythrocytes (Nakasone \& Iwanaga 1993). Enterococcus faecalis strains carry thin peritrichous fimbriae on a proportion of their cells, and the percentage of fimbriated cells varies throughout the growth cycle (Handley \& Jacob 1981). The major virulence factor of Group A (Streptococci) is $M$ protein, a fibrillar surface molecule that protects the bacteria from being ingested and killed by the host's phagocytic cells (Lancefield 1962, Phillips et al. 1981). In a previous study (Ooyama et al. 1999), fimbriae-like cell surface components were seen on the KG9502 capsular virulent strain of Lactococcus garvieae incubated with yellowtail immune serum. It was difficult to differentiate fimbriae from cell cap- sules after treatment of cells with rabbit immune serum against capsulated cells. In this study, fimbriae-like cell surface components of MS93003 and KG9408 strains were clearly demonstrated in yellowtail serum cultures. Some factor(s) in the fish serum may enhance the presence of cell-surface components of L. garvieae. However, the $\mathrm{LD}_{50}$ of Strain MS93003, carrying fimbriae-like surface components, was similar to that of NSS9310 with no cell-surface components. The role of fimbriae-like cell surface components on L. garvieae is not yet known, and further investigation is needed.

Virulent bacteriophages have been isolated and used in the typing of Lactococcus garvieae strains isolated from yellowtail (Park et al. 1997, 1998). In the present study, the KG+ phenotypes of NSS9310 and MS93003 differed in phage susceptibility to PLg-16 from the KG9408 (KG- capsular strain). Furthermore, the plaque sizes of PLgY-30 on NSS9310 and MS93003 differed from those of KG9408. KG9408 susceptibility to PLgY-16 could be induced after several subcultures on agar media supplemented with TTC (data not shown). It is suggested that these changes in phage susceptibility may be influenced by the size of the capsule.

Humoral immunity plays an important role in the protection of yellowtail from Lactococcus garvieae infection (Ooyama et al. 1999). Antigens eliciting protection in fish were reduced when the bacterial cells were kept at $121^{\circ} \mathrm{C}$ for $15 \mathrm{~min}$, indicating that they are relatively heat-labile. However, the welldeveloped cell capsule associated with virulence might not be needed to induce protection against $L$. garvieae infection. This possibility was investigated by carrying out a protein analysis of virulent KG9408 and non-virulent MS93003 and NSS9310 strains. Immunoblotting analysis using rabbit anti-KG9408 and anti-MS93003 serum showed the loss of 2 protein antigens (15 to 20 and 30 to $35 \mathrm{kDa}$ ) in NSS9310 compared to KG9408 and MS93003. Hirono et al. (1999) reported 5 different clones from a gene library of $L$. garvieae KG-phenotype cells. The reaction of recombinant proteins expressed by recombinant Escherichia coli JM109 with anti-KG- and anti-KG+ specific rabbit serum indicated that the molecular size of immunologically-detected $\mathrm{KG}$ - specific proteins of these clones was $25,26,28,30$ and $13 \mathrm{kDa}$. It is possible that there is a deficiency of immunologically-detectable proteins in NSS9310 compared with MS93003 and KG9408 when treated with rabbit immune serum, and this may provide incomplete protection to the fish. An analysis of protein profiles from KG9408, MS93003 and NSS9310 by yellowtail anti-KG9408 and antiMS93003 serum also revealed that several protein bands were missing from the NSS9310 strain compared to KG9408 and MS93003. Although analysis 
with rabbit antiserum and yellowtail antiserum revealed that some proteins were missing from NSS9310, the molecular sizes of the missing bands did not coincide with each other. The immune recognition of rabbit serum against $L$. garvieae could be different from the reaction of yellowtail serum. Formalin-killed $\mathrm{KG}+$ phenotype cells could induce high agglutinating titres against the homologous cells in yellowtail serum, but not against KG-phenotype cells. However, rabbit immunized with KG-phenotype cells induced high agglutinating titres in serum against the homologous strain (Kitao 1982, Yoshida et al. 1996).

Alim et al. (2001) reported that the cell-surface immunoprotective, $96 \mathrm{kDa}$ glycoprotein from a nonagglutinating strain of Enterococcus seriolicida (KGphenotype) is specific to an antigen on the cell surface of KG-phenotype cells. However, in the present study we could not identify the $96 \mathrm{kDa}$ protein band using the anti-KG-yellowtail serum. Immunoprotective antigens are still unidentified. Further investigations determining the molecular size of antigens are needed. Rabbit and yellowtail anti-KG9408 and anti-MS93003 sera also detected antigens in Lactococcus lactis ATCC19435. Formalin-killed L. lactis ATCC19435 induced some degree of protection in yellowtail against KG9408, but this was incomplete (data not shown). Therefore, antigens common to L. garvieae and L. lactis ATCC19435 may induce some degree of immunity in the yellowtail Seriola quinqueradiata.

Acknowledgements. This study was supported by a Grantin-Aid for Scientific Research (C, No.12660176) from The Ministry of Education, Culture, Sports, Science and Technology (MEXT) of Japan. We would like to express our thanks to Dr. V. Inglis for reviewing the manuscript. We also would like to express our thanks to Dr. J. Carson, Fish Health Unit, Department of Primary Industries, Water and Environment, Tasmania, for providing Lactococcus garvieae strains from rainbow trout.

\section{LITERATURE CITED}

Alim SR, Kawai K, Kusuda R (1996) Comparative pathogenicity study on antigenically variant strains of Enterococcus seriolicida. J Fish Dis 19:39-46

Alim SR, Hossain MA, Choedhury EK, Kusuda R (2001) G1 antigen: a cell-surface immunoprotective $96 \mathrm{kDa}$ glycoprotein from the virulent fish pathogen Enterococcus seriolicida, its purification and characterization. Lett Appl Microbiol 32:357-361

Aoki T, Takami K, Kitao T (1990) Drug resistance in a non-hemolytic Streptococcus sp. isolated from cultured yellowtail, Seriola quinqueradiata. Dis Aquat Org 8:171-177

Barnes AC, Guyot C, Hansen BG, Mackenzie K, Horne MT, Ellis AE (2002a) Resistance to serum killing may contribute to differences in the abilities of capsulate and non-capsulated isolates of Lactococcus garvieae to cause disease in rainbow trout (Oncorhynchus mykiss L.). Fish Shellfish Immunol 12:155-168

Barnes AC, Guyot C, Hansen BG, Horne MT, Ellis AE (2002b) Antibody increases phagocytosis and killing of Lactococcus garvieae by rainbow trout (Oncorhynchus mykiss L.) macrophages. Fish Shellfish Immunol 12:181-186

Carson J, Gudkovs N, Austin N (1993) Characteristics of an Enterococcus-like bacterium from Australia and South Africa, pathogenic for rainbow trout, Oncorhynchus mykiss (Walbaum). J Fish Dis 16:381-388

Chen SC, Lin YD, Liaw LL, Wang PC (2001) Lactococcus garvieae infection in the giant freshwater prawn Macrobranchium rosenbergii confirmed by polymerase chain reaction and 16S rDNA sequencing. Dis Aquat Org 45: 45-52

Eldar A, Ghittino C, Asanta L, Bozzetta E, Goria M, Prearo M, Bercovier H (1996) Enterococcus seriolicida is a junior synonym of Lactococcus garvieae, a causative agent of septicemia and meningoencephalitis in fish. Curr Microbiol 32:85-88

Eldar A, Goria M, Ghittino C, Zlotkin A, Bercovier H (1999) Biodiversity of Lactococcus garvieae strains isolated from fish in Europe, Asia and Australia. Appl Environ Microbiol 65:1005-1008

Handley PS, Jacob AE (1981) Some structural and physiological properties of fimbriae of Streptococcus faecalis. J Gen Microbiol 127:289-293

Hirono I, Yamashita H, Park C, Yoshida T, Aoki T (1999) Identification of genes in a KG-phenotype of Lactococcus garvieae, a fish pathogenic bacterium, whose proteins react with anti-KG- rabbit serum. Microb Pathog 27: 407-417

Iida T, Wakabayashu H, Egusa S (1982) Vaccination for control of streptococcal disease in cultured yellowtail. Fish Pathol 21:33-38

Kitao T (1982) The methods for detection of Streptococcus sp. Causative bacteria of streptococcal disease of cultured yellowtail, Seriola quinqueradiata, especially, their cultural, biochemical and serological properties. Fish Pathol 17:17-26 (in Japanese with English abstract)

Kitao T (1993) Streptococcal infection. In: Inglis V, Roberts RJ, Bromage NR (eds) Bacterial diseases of fish. Blackwell Scientific Publications, Oxford, p 196-210

Kusuda R, Kawai K, Salati F, Banner CR, Fryer JL (1991) Enterococcus seriolicida sp. nov., a fish pathogen. Int J Syst Bacteriol 41:406-409

Laemmli UK (1970) Cleavage of the structural proteins during the assembly of the head of bacteriophage T4. Nature 227: 680-685

Lancefield RC (1962) Current knowledge of type specific M antigens of group A Streptococci. J Immunol 85:307-313

Marques LRM, Toledo MRF, Silva NP, Magalhaes M, Trabulsi LR (1984) Invasion of Hela cells by Edwardsiella tarda. Curr Microbiol 10:129-132

Nakasone N, Iwanaga M (1993) Cell-associated haemagglutinin of classical Vibrio cholerae O1 with reference to intestinal adhesion. FEMS Microbiol Lett 113:67-70

Okada T, Minami T, Ooyama T, Yasuda H, Yoshida T (2000) Capsular and non-capsular antigen localization on Lactococcus garvieae isolated from yellowtail, Seriola quinqueradiata. Fish Sci (Tokyo) 66:992-994

Ooyama T, Kera A, Okada T, Inglis V, Yoshida T (1999) The protective immune response of yellowtail Seriola quinqueradiata to the bacterial fish pathogen Lactococcus garvieae. Dis Aquat Org 37:121-126

Park KH, Matsuoka S, Nakai T, Muroga K (1997) A virulent bacteriophage of Lactococcus garvieae (formerly Entero- 
coccus seriolicida) isolated from yellowtail Seriola quinqueradiata. Dis Aquat Org 29:145-149

Park KH, Kato H, Nakai T, Muroga K (1998) Phage typing of Lactococcus garvieae (formerly Enterococcus seriolicida) a pathogen of cultured yellowtail. Fish Sci (Tokyo) 64:62-64

Paterson WD, Douglas RJ, Grinyer I, McDermott LA (1969) Isolation and preliminary characterization of some Aeromonas salmonicida bacteriophages. J Fish Res Board Can 26:629-632

Phillips GN Jr, Flicker PF, Cohen C, Manjula BN, Fischetti VA (1981) Streptococcal M protein: alpha-helical coiled-coli structure and arrangement on the cell surface. Proc Natl Acad Sci USA 78:4689-4693

Reed LJ, Muench H (1938) A simple method of estimating fifty percent end point. Am J Hyg 9:267-287

Roberson BS (1990) Bacterial agglutination. In: Stolen JS, Fletcher TC, Anderson DP, Roberson BS, van Muiswinkel WB (eds) Techniques in fish immunology. SOS Publications, Fair Haven, NJ, p 81-86

Sato H, Ninomiya M, Kawai K, Kusuda R (1996) Protection and opsonic activity in the serum of yellowtail Seriola quinqueradiata immunized with Enterococcus seriolicida

Editorial responsibility: David Bruno,

Aberdeen, Scotland, UK formalin-killed cells. Nippon Suisan Gakkaishi 62:939-940 (in Japanese with English abstract)

Schmidtke LM, Carson J (1999) Induction, characterization and pathogenicity in rainbow trout Oncorhynchus mykiss (Walbaum) of Lactococcus garvieae L-forms. Vet Microbiol 69:287-300

Smith SA (1992) Affinity purification of serum immunoglobulin from fish. In: Stolen JS, Fletcher TC, Anderson DP, Kaattari SL, Rowley AF (eds) Techniques in fish immunology. SOS Publications, Fair Haven, NJ, p 125-130

Towbin H, Staehelin T, Gordon J (1979) Electrophoretic transfer of proteins from polyacrylamide gels to nitrocellulose sheets: procedure and some applications. Proc Natl Acad Sci USA 76:4350-4354

Yoshida T, Eshima T, Wada Y, Yamada Y, Kakizaki E, Sakai M, Kitao T, Inglis V (1996) Phenotypic variation associated with anti-phagocytic factor in the bacterial fish pathogen, Enterococcus seriolicida. Dis Aquat Org 25: 81-86

Yoshida T, Endo M, Sakai M, Inglis V (1997) A cell capsule with possible involvement in resistance to opsonophagocytosis in Enterococcus seriolicida from yellowtail, Seriola quinqueradiata. Dis Aquat Org 29:233-235

Submitted: December 12, 2001; Accepted: February 26, 2002 Proofs received from author(s): September 17, 2002 